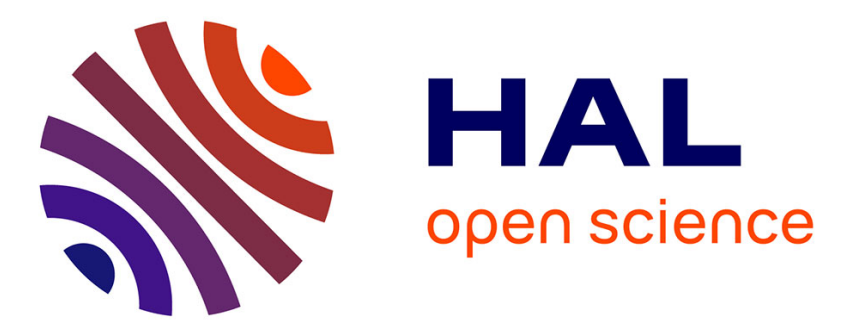

\title{
Mapping near-inertial variability in the SE Bay of Biscay from HF radar data and two offshore moored buoys
}

\author{
Anna Rubio, Gilles Reverdin, A. Fontán, M. González, Julien Mader
}

\section{To cite this version:}

Anna Rubio, Gilles Reverdin, A. Fontán, M. González, Julien Mader. Mapping near-inertial variability in the SE Bay of Biscay from HF radar data and two offshore moored buoys. Geophysical Research Letters, 2011, 38, pp.19607. 10.1029/2011GL048783 . hal-00755396

\section{HAL Id: hal-00755396 https://hal.science/hal-00755396}

Submitted on 4 Nov 2021

HAL is a multi-disciplinary open access archive for the deposit and dissemination of scientific research documents, whether they are published or not. The documents may come from teaching and research institutions in France or abroad, or from public or private research centers.
L'archive ouverte pluridisciplinaire HAL, est destinée au dépôt et à la diffusion de documents scientifiques de niveau recherche, publiés ou non, émanant des établissements d'enseignement et de recherche français ou étrangers, des laboratoires publics ou privés. 


\title{
Mapping near-inertial variability in the SE Bay of Biscay from HF radar data and two offshore moored buoys
}

\author{
A. Rubio, ${ }^{1}$ G. Reverdin, ${ }^{2}$ A. Fontán, ${ }^{1}$ M. González, ${ }^{1}$ and J. Mader ${ }^{1}$ \\ Received 12 July 2011; revised 12 September 2011; accepted 12 September 2011; published 15 October 2011.
}

[1] HF radar surface current data together with data from two operational offshore oceanographic buoys located over the slope are used to map the variability associated with the near-inertial waves, during a target year (2009), in the SE Bay of Biscay. The results obtained show the complex 4D distribution of inertial oscillations in this area. We find a very pronounced horizontal structure across the area with ranges of a factor 5 in near-inertial kinetic energy. This pattern presents also strong seasonal variability, with a peak in KE closer to the shelf-break in summer, whereas winter maximum is weaker and located further to the north-east. The mooring data indicate more trapping near the surface in summer. These patterns are discussed in relation to the known seasonal differences in atmospheric/ buoyancy forcing and the characteristics of the sub-inertial surface velocity field. Citation: Rubio, A., G. Reverdin, A. Fontán, M. González, and J. Mader (2011), Mapping nearinertial variability in the SE Bay of Biscay from HF radar data and two offshore moored buoys, Geophys. Res. Lett., 38, L19607, doi:10.1029/2011GL048783.

\section{Introduction}

[2] Inertial oscillations at the ocean surface are mainly wind-driven and their characteristics in the open ocean have been widely described and studied with regard to the main factors forcing their distribution and propagation, i.e. beta plane, stratification conditions and background field [Gill, 1982; Lee and Niiler, 1998]. Other studies have focused on areas close to the coastal boundaries, where non spatially-uniform winds, steep topography and intense coastal circulations and fronts also play a key role, adding complexity to the near-inertial oscillations evolution and distribution [Davies and Xing, 2005; Tintoré et al., 1995; Xing et al., 2004; Kohut et al., 2006]. The impact of these waves on the vertical mixing and exchanges between the surface and the ocean interior or the advection of particles has been evocated in several occasions [Pingree et al., 1982; van Haren et al., 1999; Tintoré et al., 1995].

[3] The ocean circulation in the SE Bay of Biscay shows relatively complex patterns. Over the shelf, the circulation is driven mainly by winds [González et al., 2004] which vary seasonally in strength (more intense and more persistent in winter, weaker and more variable in summer) and direction (often from the SW in winter and from the NW in summer). Over the slope, the Iberian Poleward Current flows towards the east (north) off the Spanish (French) coasts with rela-

\footnotetext{
${ }^{1}$ Marine Research Division, AZTI-Tecnalia, Pasaia, Spain.

${ }^{2}$ LOCEAN, IPSL, INSU, CNRS, UPMC, Paris, France.
}

Copyright 2011 by the American Geophysical Union. 0094-8276/11/2011GL048783 tively weak mean currents $\left(\sim 0.2 \mathrm{~m} . \mathrm{s}^{-1}\right)$, a marked seasonality (larger currents in winter along the northern Spanish slope) and significant mesoscale variability [Le Cann and Serpette, 2009]. A clear seasonal cycle dominates the density distributions within the upper $100 \mathrm{~m}$ of the water column, with a surface mixed layer that shows temperatures over $20^{\circ} \mathrm{C}$ and depths of $40 \mathrm{~m}$ or less between July and September (A. Rubio et al., Seasonal to tidal variability of currents and temperature in waters of the continental slope, southeastern Bay of Biscay, submitted to Journal of Marine Systems, 2011). At shorter time-scales, the variability is dominated by tides (mainly semidiurnal and weaker than in other areas of the Bay [Le Cann, 1990]) and inertial waves. Recent work has shown that inertial oscillations are the main process responsible for the vertical current shear in the area, and, thus, they may contribute significantly to the shearinduced mixing (A. Rubio et al., submitted manuscript, 2011). This could have significant impact on the availability of nutrients in a key area for spawning and life cycle of several pelagic species [Irigoien et al., 2008]. The recent availability of HF radar data and the data from two offshore moorings permits to study the structure of the near-inertial oscillations in this area, with high spatial and temporal resolutions.

\section{Data and Methods}

[4] HF radar-derived surface hourly currents were collected in 2009 by means of a CODAR Seasonde system which consisted of two stations located near the Spanish coast, overlooking the south-east Bay of Biscay (Figure 1a). The antennae (emitting at $40 \mathrm{KHz}$ broadband and $4.5 \mathrm{MHz}$ frequency) covered a $150 \mathrm{~km}$ range with $5 \mathrm{~km}$ radial and $5^{\circ}$ angular resolutions. Velocity data were processed from the spectra of the received echoes every 20 minutes using the MUSIC algorithm [Schmidt, 1986]. The radial velocities were stored hourly after applying a centered $3 \mathrm{~h}$ running mean average, converted to total fields (using a least mean squares algorithm with a spatial interpolation radius of $20 \mathrm{~km}$ ) and gridded into a $5 \mathrm{~km}$ resolution regular orthogonal mesh. The data at nodes with a crossing angle between radials under $30^{\circ}$ and radial velocities over $120 \mathrm{~cm} . \mathrm{s}^{-1}$ were systematically removed. In-situ data were obtained by means of two buoys moored over the upper part of the slope in water depths of 550 and $450 \mathrm{~m}$ (Figure 1a). They measured hourly currents at $1.5 \mathrm{~m}$ depth by an ADC $(2 \mathrm{MHz})$ located at the base of the surface float and between 12.5 and $150 \mathrm{~m}$ (within $8 \mathrm{~m}$ vertical bins) by a downward-looking ADCP $(150 \mathrm{kHz})$. The 3 -days looping trajectory shown in Figure 1a (black line) was obtained from averaging the positions of 5 SVP WOCE-type drifting buoys deployed at $2.05^{\circ} \mathrm{W}, 43.88^{\circ} \mathrm{N}$, in the framework of the French 
a)

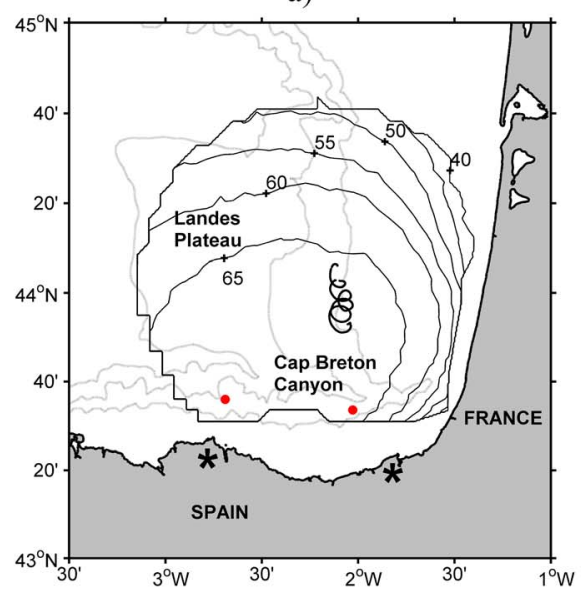

c)

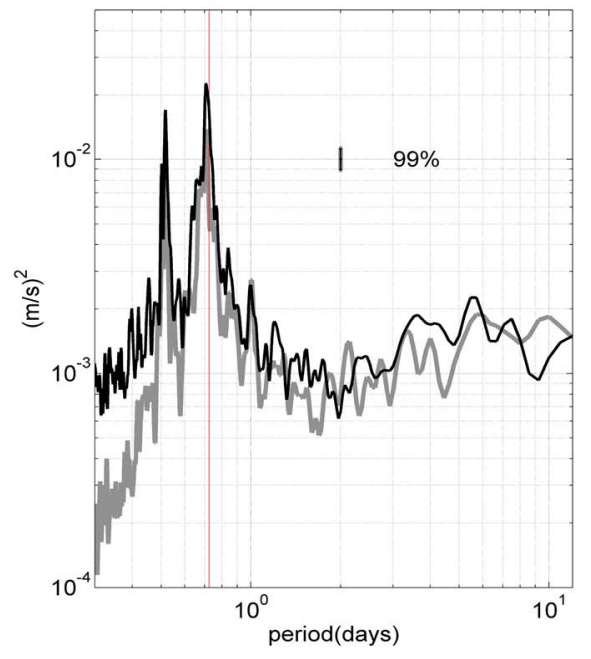

b)

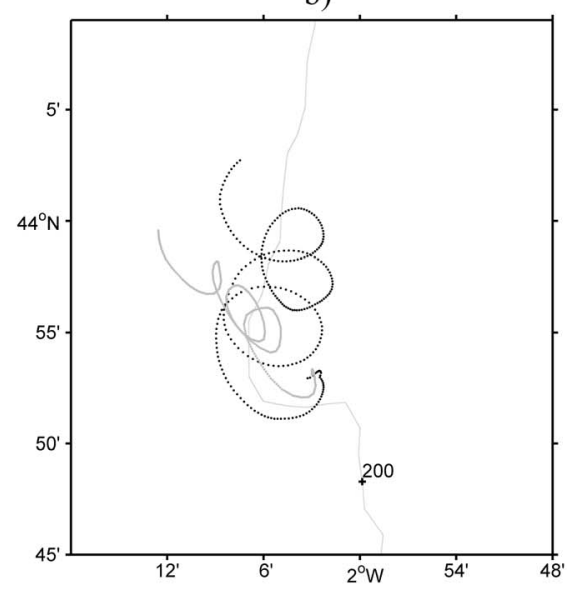

d)

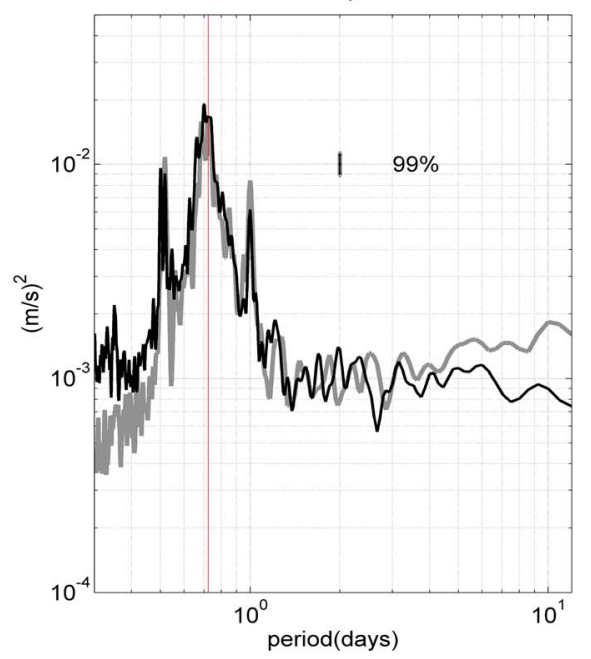

Figure 1. (a) Spatial availability of radar data (\%) in the study area (SE Bay of Biscay) for the target year 2009. Asterisks locate the two HF radar sites, gray points the positions of Donostia (the easternmost) and Matxitxako moorings and the black thick line the trajectory of the drifter on 17-19 May 2009. Isobaths: 200, 1000 and 2000 m. (b) The radar-derived trajectory (gray line) is superimposed to the trajectory of the drifter buoy (dotted black line). Isobath: $200 \mathrm{~m}$. (c) Matxitxako and (d) Donostia power spectra inferred from HF radar (gray line) and the mooring currents at $1.5 \mathrm{~m}$ (black line).

GOGASMOS oceanographic campaign on 17 May 2009 (G. Reverdin et al., Fresh water from the Bay of Biscay shelves in 2009, submitted to Journal of Marine Systems, 2011). They were basically composed of a spherical float $\sim 40 \mathrm{~cm}$ in diameter and a $10 \mathrm{~m}$ long holey-sock drogue centered at $8 \mathrm{~m}$ depth. The buoys remained less than $3 \mathrm{~km}$ apart during the 3 days trajectory and GPS positions were acquired every 30 minutes.

[5] To compute the power spectra we applied the LombScargle periodogram [Lomb, 1976; Scargle, 1982]. Spectra were calculated by dividing the time-series into successive 30-day segments, with a 15-day overlap; subsequently, the resulting spectra were band-averaged to obtain accurate spectral calculations (total number of degrees of freedom between 30 and 100). The spectra for both components were summed to provide information on the spectral distribution of the total kinetic energy (hereinafter KE) per frequency band. Finally, a 10th order digital Butterworth filter [Emery and Thomson, 2001] was applied to the time series (and each velocity component): a pass band, $14 \mathrm{~h}<\mathrm{T}<20 \mathrm{~h}$, to calculate near-inertial velocities and a low pass, $\mathrm{T}>30 \mathrm{~h}$, to obtain the sub-inertial currents. The filtered data series were then integrated to calculate the KE distributions as the sum of the square of the two velocity components. For the KE maps, the analysis was performed for two different periods: "winter" (from November to February) and "summer" (from June to September).

\section{Radar Versus In-Situ Data}

[6] Although HF radar surface currents have been validated by several authors [Graber et al., 1997; Paduan and Rosenfeld, 1996; Kohut and Glenn, 2003], in order to obtain estimation on the accuracy of the HF radar configuration used here, radar currents have been compared with currents at $1.5 \mathrm{~m}$ and the drifter trajectory (Table 1). In both cases, in-situ data have been averaged using a 3-h running mean to be consistent with the processing of radar data. The comparison between different measuring systems is not straightforward since each system measure currents over 
Table 1. Summary of Comparisons Between In-Situ, at 1.5 and $12 \mathrm{~m}$ Depth From Moorings and at $8 \mathrm{~m}$ Depth From the Drifter, and Radar-Derived Velocities at the Corresponding Nodes ${ }^{\mathrm{a}}$

\begin{tabular}{|c|c|c|c|c|c|c|c|c|c|c|c|}
\hline \multirow[b]{3}{*}{ Data Set 1} & \multirow[b]{3}{*}{ Data Set 2} & \multicolumn{4}{|c|}{$\operatorname{RMS}\left(\mathrm{m} \cdot \mathrm{s}^{-1}\right)$} & \multirow{2}{*}{\multicolumn{2}{|c|}{$\begin{array}{l}\text { RMSD Data } \\
\text { Set } 1 \text { vs. Data } \\
\text { set } 2\left(\mathrm{~m} \cdot \mathrm{s}^{-1}\right) \\
\end{array}$}} & \multirow{2}{*}{\multicolumn{2}{|c|}{$\begin{array}{c}\text { R Data Set } 1 \\
\text { vs. Data Set } 2 \\
\end{array}$}} & \multirow{2}{*}{\multicolumn{2}{|c|}{$\begin{array}{c}\text { MRD Data Set } 1 \\
\text { vs. Data Set } 2\end{array}$}} \\
\hline & & \multicolumn{2}{|c|}{ Data Set 1} & \multicolumn{2}{|c|}{ Data Set 2} & & & & & & \\
\hline & & $\mathrm{u}$ & $\mathrm{V}$ & $\mathrm{u}$ & $\mathrm{v}$ & $\mathrm{u}$ & $\mathrm{v}$ & $\mathrm{u}$ & $\mathrm{V}$ & $\mathrm{u}$ & V \\
\hline Matxitxako $1.5 \mathrm{~m}$ & Radar & 0.16 & 0.10 & 0.13 & 0.08 & 0.08 & 0.08 & 0.86 & 0.64 & -1.10 & -0.92 \\
\hline Matxitxako $12 \mathrm{~m}$ & Radar & 0.15 & 0.09 & 0.13 & 0.08 & 0.10 & 0.09 & 0.74 & 0.50 & -1.85 & -2.70 \\
\hline Donostia $1.5 \mathrm{~m}$ & Radar & 0.12 & 0.11 & 0.11 & 0.12 & 0.10 & 0.13 & 0.53 & 0.35 & -1.31 & 0.44 \\
\hline Donostia $12 \mathrm{~m}$ & Radar & 0.10 & 0.08 & 0.11 & 0.12 & 0.10 & 0.13 & 0.37 & 0.21 & 0.84 & -0.22 \\
\hline Drifter & Radar & 0.27 & 0.27 & 0.16 & 0.21 & 0.16 & 0.09 & 0.72 & 0.91 & -0.22 & -0.01 \\
\hline Matxitxako $1.5 \mathrm{~m}$ & Matxitxako $12 \mathrm{~m}$ & 0.16 & 0.10 & 0.15 & 0.09 & 0.10 & 0.09 & 0.80 & 0.60 & 1.97 & 0.60 \\
\hline Donostia $1.5 \mathrm{~m}$ & Donostia $12 \mathrm{~m}$ & 0.12 & 0.11 & 0.10 & 0.08 & 0.12 & 0.12 & 0.37 & 0.28 & -1.36 & -0.83 \\
\hline
\end{tabular}

${ }^{\text {a }}$ To give an idea on the vertical shear at each mooring location, the in-situ current measurements at 1.5 and $12 \mathrm{~m}$ are also compared. The Root Mean Square (RMS) for each velocity component of the compared data set is given in columns 1 to 4 . The RMS deviations (RMSD), the correlation coefficient (R), and the Mean Relative Differences (MRD) between data sets, for each velocity component, are shown in columns 5 to 10.

different spatial and temporal scales, and has its own inaccuracies. At $4.5 \mathrm{MHz}$ frequency, the measurements made by the radar integrate currents vertically within the first $2-3 \mathrm{~m}$ of the water column [Laws, 2001]; moreover, the radar horizontal resolution ranges geographically from several kms near the antennas, south of the domain, to several tens of $\mathrm{kms}$ at the middle of it. As a result, any vertical or horizontal shear in currents will contribute to the differences observed between measurements [Graber et al., 1997]. Over the slope, better agreement is found for the EW component and Matxitxako location, which could be linked to the less variable regime of the along-slope circulation and lower vertical shear values. The comparison with the pseudoeulerian velocities derived from the drifter shows slightly poorer agreement, which was expected as radar inaccuracies increase with the distance to the antennas. The looping trajectory described by the drifters was induced by intense inertial oscillations after a relatively strong $\left(\sim 10-20 \mathrm{~m} . \mathrm{s}^{-1}\right)$ westerly wind event occurring on 14-15 May (which changed to southerly on 16 May, and gradually relaxed during the next 2 days). A lagrangian particle-tracking model [Ferrer et al., 2009] has been applied to radar data to reproduce the observed trajectory (Figure 1b). The comparison of the two trajectories shows that the amplitude of the oscillation described by the radar is smaller, which could be due to the spatial smoothing applied to radar measurements. Moreover, the mean drift direction for the radar-derived trajectory is rotated to the $\mathrm{W}$ with respect to the in-situ trajectory, in accordance with expectation for a southerly wind (since the in-situ trajectory describes the motion of a deeper layer, and therefore more to the right of the wind). Both issues would also contribute to the RMS differences observed.

[7] Finally, the power spectra of ADC currents at $1.5 \mathrm{~m}$ and $\mathrm{HF}$ radar at the closest nodes show that no significant differences in amplitude between buoys and radar are observed at the main peaks and within the band from some hours to some days (for periods under 6 hours radar spectra show a marked energy drop, probably linked to the running average applied to radial velocity data in order to increase the robustness of the resulting fields). The dominant peaks are located around the diurnal, semi-diurnal and local inertial $(\sim 0.71 \mathrm{~d})$ periods (Figures $1 \mathrm{c}$ and $1 \mathrm{~d})$ with an energy maximum (KE values around $10^{-2} \mathrm{~m}^{2} \cdot \mathrm{s}^{-2}$ ) located around the local inertial frequency. Spatial variability is observed, with a higher and wider KE peak around the local inertial frequency at Donostia. The spatial differences in the relative amplitude of the main peaks observed between the buoys are consistent with those observed between the corresponding radar nodes, which prove the sensitivity of radar data (despite the spatial smoothing) to the spatial variability.

\section{Near-Inertial KE Distribution}

[8] The vertical distribution of near-inertial KE is examined at the mooring sites (Figure 2) and compared with the radar measurements at the closest nodes. Good accordance is found between radar and ADC $1.5 \mathrm{~m}$ data, with the radar near-inertial derived currents slightly more energetic most of the time. Vertically, near-inertial KE values appear to be significantly higher from the surface to $50 \mathrm{~m}$ depth (Figures 2b and 2e). Spatially, significant differences are found between both moorings, with higher values at Donostia where surface inertial events (which are confined to the upper 20-30 m, above the seasonal thermocline) are amplified from April to August, in relation to the stronger stratification. At Matxitxako, surface KE levels for the same period are lower at the surface, although the energy at deeper levels is similar to that at Donostia. Higher energy levels at intermediate depths are found at both locations from September to November, as the mixed layer deepens. Specifically, high KE levels (involving, at least, the first $150 \mathrm{~m}$ of the water column) are observed during winter, as a response to two particularly strong mixing events: Klaus explosive cyclogenesis on 23-24 January [González et al., 2009] and 1-10 November intense storms.

[9] The near-inertial surface KE for the radar data shows a complex horizontal distribution, which varies seasonally. The mean values of near-inertial KE are compared with the sub-inertial KE and relative vorticity (hereinafter RV) to give an idea on the influence of the background motion on the inertial wave fields observed (Figure 3). During summer (in conditions of stratification and weaker but more variable winds) the surface $\mathrm{KE}$ values are much more intense and centered in the middle of the domain, with a maximum over the north-east of the Landes Plateau and decrease progressively towards the coast. During winter, conversely, the observed near inertial KE at surface levels is significantly 


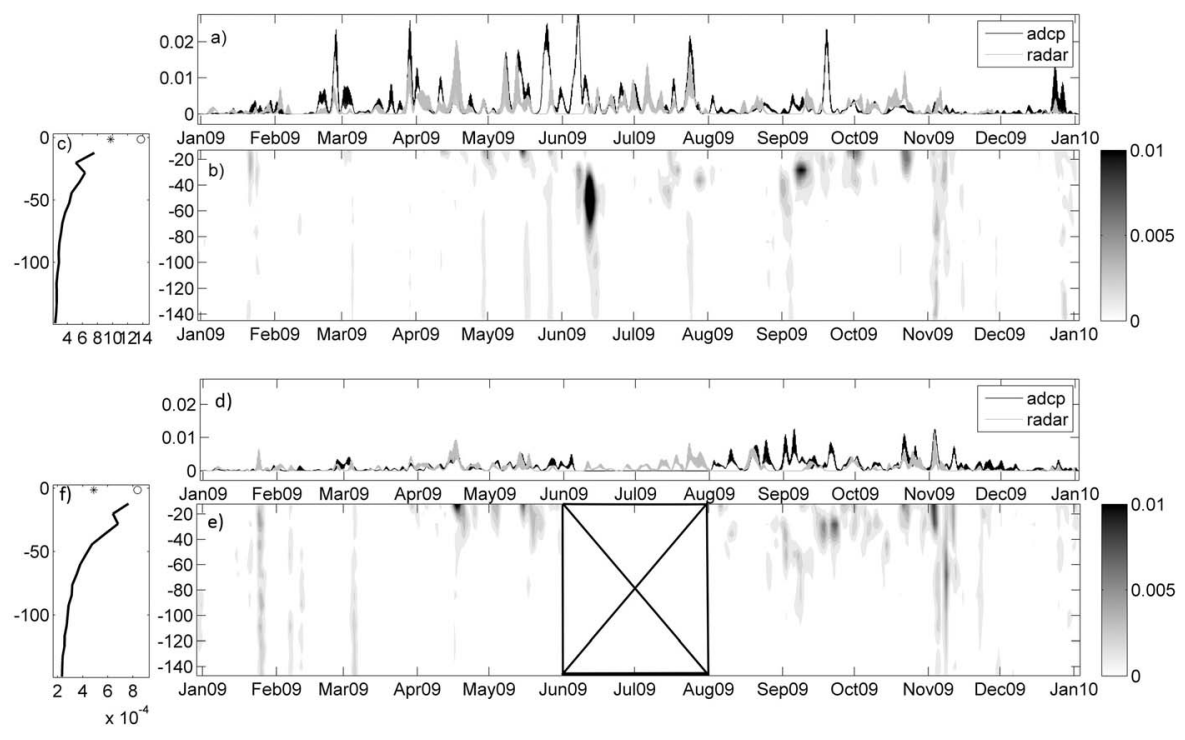

Figure 2. Time-depth variability of near-inertial KE $\left(\mathrm{m}^{2} \cdot \mathrm{s}^{-2}\right)$ over the slope for $(\mathrm{a}-\mathrm{c})$ Donostia and (d-f) Matxitxako moorings and the corresponding radar nodes. Figures $2 \mathrm{a}$ and $2 \mathrm{~d}$ show surface near-inertial KE contents from HF radar (gray line) and currents at $1.5 \mathrm{~m}$ (black line). Figures $2 \mathrm{~b}$ and $2 \mathrm{e}$ show time-depth plots of near-inertial KE along the ADCP vertical range (from 12.5 to $148.5 \mathrm{~m}$ within $8 \mathrm{~m}$ bins). Figures $2 \mathrm{c}$ and $2 \mathrm{f}$ show mean near-inertial KE vertical profile for the targeted year for ADCP currents (bold line) and surface current data (an asterisk is used for the ADC $1.5 \mathrm{~m}$ and a circle for the corresponding radar node).

a)
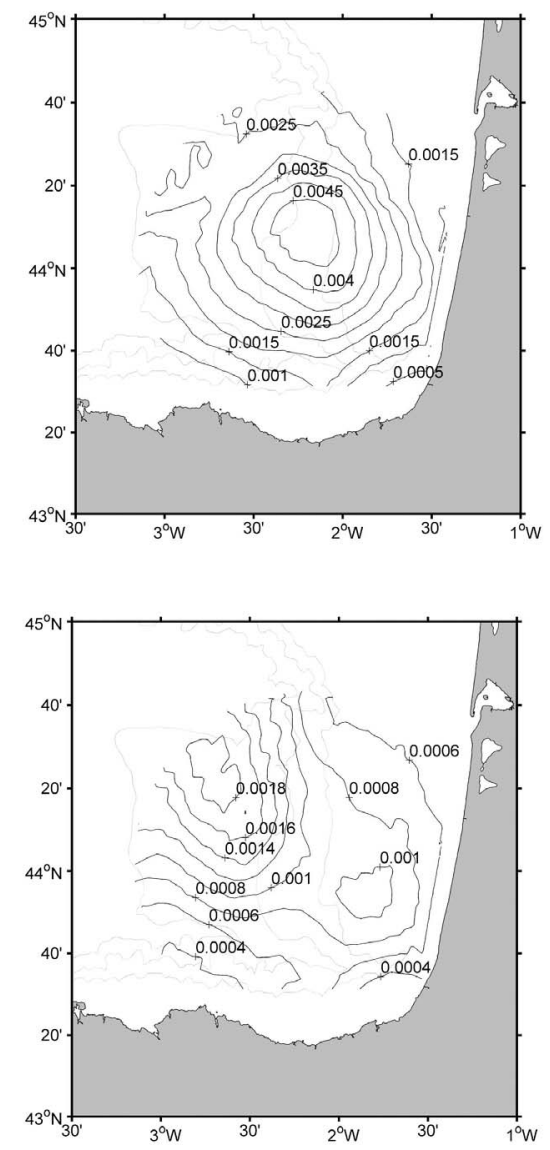

b)
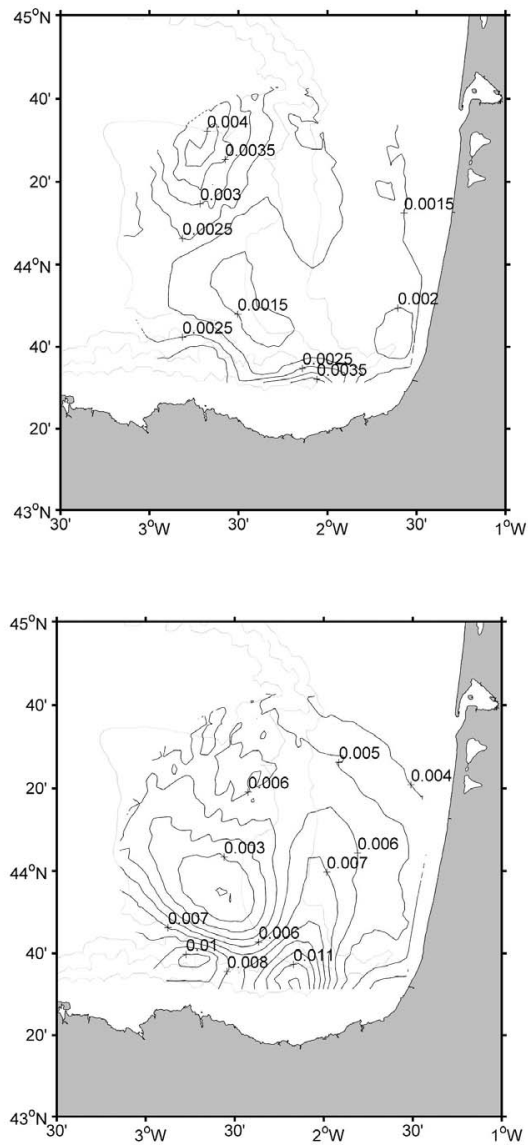

c)
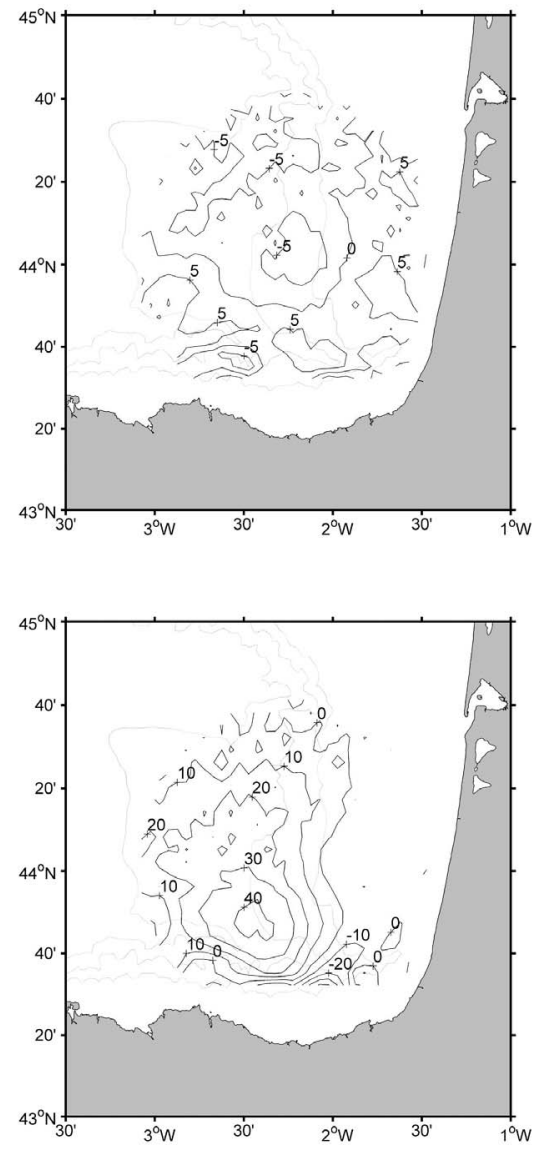

Figure 3. Mean values of (a) near-inertial $\mathrm{KE}\left(\mathrm{m}^{2} . \mathrm{s}^{-2}\right)$, (b) sub-inertial $\mathrm{KE}\left(\mathrm{m}^{2} . \mathrm{s}^{-2}\right)$, (c) sub-inertial relative vorticity $\left(10-6 \mathrm{~s}^{-1}\right)$ for (top) summer and (bottom) winter periods at the SE Bay of Biscay. Isobaths: 200, 1000 and $2000 \mathrm{~m}$. 
lower. This was rather expected as, in winter, a more persistent wind field would be less favorable to the development of oscillations and a deeper mixed layer would lead to smaller amplitudes. The near-inertial $\mathrm{KE}$ is more intense at the NW of the domain over the deeper part of the study area and decreases progressively towards shallower ground depths. The relationship between the observed KE distribution and the characteristics of the background field is not straightforward, namely during summer, when the background field, consisting in an anticyclonic pattern (negative $\mathrm{RV}$ ), is weak (mean current under $0.05 \mathrm{~m} . \mathrm{s}^{-1}$ ). During winter, the mean circulation pattern changes to a cyclonic more intense circulation, with maximum intensity over the upper slope (mean current speeds of $0.1 \mathrm{~m} . \mathrm{s}^{-1}$ ) and markedly stronger RV gradients. In this case, the near-inertial oscillations decrease in the areas where the mean flow is intense and presents strong RV positive values (in accordance with the theory introduced by Kunze [1985]), being confined to the north-west of the domain, over the deeper part of the slope.

\section{Conclusions}

[10] HF radar-derived surface currents and currents from two moorings over the slope are used to map the nearinertial variability at the SE Bay of Biscay. The results obtained show the complex 4D distribution of inertial oscillations. A very pronounced horizontal structure across the area with ranges of a factor 5 in near-inertial $\mathrm{KE}$ is observed. This pattern presents strong seasonal variability: more trapping near the surface, with a peak in KE closer to the shelf-break, in summer, whereas winter surface maximum is weaker and located further to the north-west. While in summer the relationship between the observed KE distribution and the characteristics of the weak background velocity field observed is not straightforward, in winter, the near-inertial oscillations decrease in the areas where the mean flow is more intense and present stronger RV positive values. Vertically and over the slope, the highest energies are mainly confined to the mixed layer during summer but they progressively propagate to deeper levels as the seasonal stratification weakens.

[11] The marked variability observed in the time-space distribution of the near-inertial KE, and the potential role of these oscillations in the vertical shear-induced mixing, suggest that they could have a major impact in the modulation of biogeochemical cycles in the area. Although the near-inertial KE surface distribution is partially influenced by the seasonal variability in winds, buoyancy and background circulation, other processes linked to internal wave propagation characteristics and wave interactions with coast and bathymetry [Millot and Crépon, 1981; Klinck et al., 1981; Tintoré et al., 1995; Xing et al., 2004] could also play a major role and deserve further investigation.

[12] Acknowledgments. Authors thank the Meteorology and Emergencies Directorate, the Department of Industry, Trade and Tourism and Department of Transport and Civil Works of the Basque Government. Part of this work has been undertaken within the framework of the French EPIGRAM project (ANR/LEFE-IDAO). We also thank the sampling staff of the Marine Research Division, and V. Fernández from Qualitas Remos and L. Solabarrieta for their work on HF radar data processing. Finally, the authors would like to thank the two anonymous reviewers whose com- ments helped to improve the quality of this work. This is contribution number 553, of the Marine Research Division of AZTI-Tecnalia.

[13] The Editor thanks two anonymous reviewers for their assistance in evaluating this paper.

\section{References}

Davies, A. M., and J. Xing (2005), The effect of a bottom shelf front upon the generation and propagation of near-inertial internal waves in the coastal ocean, J. Phys. Oceanogr., 35, 976-990, doi:10.1175/JPO2732.1. Emery, W. J., and R. E. Thomson (2001), Data Analysis Methods in Physical Oceanography, 654 pp., Elsevier Sci., Amsterdam.

Ferrer, L., A. Fontán, J. Mader, G. Chust, M. González, V. Valencia, Ad. Uriarte, and M. B. Collins (2009), Low-salinity plumes in the oceanic region of the Basque Country, Cont. Shelf Res., 29, 970-984, doi:10.1016/j.csr.2008.12.014.

Gill, A. E. (1982), Atmosphere-Ocean Dynamics, Academic, New York.

González, M., Ad. Uriarte, A. Fontán, J. Mader, and P. Gyssels (2004), Marine dynamics, in Oceanography and Marine Environment of the Basque Country, edited by A. Borja and M. Collins, Elsevier Oceanogr. Ser., vol. 70, pp. 133-157, Elsevier, Amsterdam.

González, M., et al. (2009), Explosive cyclogenesis of extra-tropical cyclone Klaus and its impact on the water column stability in the Bay of Biscay, GLOBEC Int. Newsl., 15(2), 59.

Graber, H. C., B. K. Haus, L. K. Shay, and R. D. Chapman (1997), HF radar comparisons with moored estimates of current speed and direction: Expected differences and implications, J. Geophys. Res., 102, 18,74918,766, doi:10.1029/97JC01190.

Irigoien, X., U. Cotano, G. Boyra, M. Santos, P. Alvarez, P. Ortheguy, E. Etxebeste, A. Uriarte, L. Ferrer, and L. Ibaibarriaga (2008), From egg to juvenile in the Bay of Biscay: spatial patterns of anchovy (Engraulis encrasicolus) recruitment in a non-upwelling region, Fish. Oceanogr., 17(6), 446-462, doi:10.1111/j.1365-2419.2008.00492.x.

Klinck, J. M., L. J. Pietrafesa, and G. S. Janowitz (1981), Continental shelf circulation induced by a moving, localized wind stress, J. Phys. Oceanogr., 11,836-848, doi:10.1175/1520-0485(1981)011<0836:CSCIBA $>2.0$. CO;2.

Kohut, J., and S. Glenn (2003), Calibration of HF radar surface current measurements using measured antenna beam patterns, J. Atmos. Oceanic Technol., 20, 1303-1316, doi:10.1175/1520-0426(2003)020<1303: IHRSCM $>2.0 . \mathrm{CO} ; 2$

Kohut, J. T., S. M. Glenn, and J. D. Paduan (2006), Inner-shelf response to tropical storm Floyd, J. Geophys. Res., 111, C09S91, doi:10.1029/ 2003JC002173.

Kunze, E. (1985), Near-inertial wave propagation in geostrophic shear, $J$. Phys. Oceanogr., 15, 544-565, doi:10.1175/1520-0485(1985) $015<0544$ :NIWPIG $>2.0 . \mathrm{CO} ; 2$.

Laws, K. (2001), Measurements of near surface ocean currents using HF radar, M.S. thesis, Univ. of Calif., Santa Cruz.

Le Cann, B. (1990), Barotropic tidal dynamics of the Bay of Biscay shelf: Observations, numerical modelling and physical interpretation, Cont. Shelf Res., 10, 723-758, doi:10.1016/0278-4343(90)90008-A.

Le Cann, B., and A. Serpette (2009), Intense warm and saline upper ocean inflow in the southern Bay of Biscay in autumn-winter 2006-2007, Cont. Shelf Res., 29, 1014-1025, doi:10.1016/j.csr.2008.11.015.

Lee, D.-K., and P. P. Niiler (1998), The inertial chimney: The near-inertial energy drainage from the ocean surface to the deep layer, J. Geophys. Res., 103, 7579-7591, doi:10.1029/97JC03200.

Lomb, N. R. (1976), Least-squares frequency analysis of unequally spaced data, Astrophys. Space Sci., 39, 447-462, doi:10.1007/BF00648343.

Millot, C., and M. Crepon (1981), Inertial oscillations on the continental shelf of the Gulf of Lions: Observation and theory, J. Phys. Oceanogr., 11, 639-657, doi:10.1175/1520-0485(1981)011<0639:IOOTCS $>2.0$. $\mathrm{CO} ; 2$.

Paduan, J. D., and L. Rosenfeld (1996), Remotely sensed surface currents in Monterey Bay from shore-based HF radar (Coastal Ocean Dynamics Application Radar), J. Geophys. Res., 101, 20,669-20,686, doi:10.1029/ 96JC01663.

Pingree, R. D., G. T. Mardell, P. M. Holligan, D. K. Griffiths, and J. Smithers (1982), Celtic Sea and Armorican Current structure and the vertical distributions of temperature and chlorophyll, Cont. Shelf Res., 1, 99-116, doi:10.1016/0278-4343(82)90033-4.

Scargle, J. (1982), Studies in astronomical time-series analysis. II - Statistical aspects of spectral analysis of unevenly spaced data, Astrophys. J., 263, 835-853, doi:10.1086/160554.

Schmidt, R. O. (1986), Multiple emitter location and signal parameter estimation, IEEE Trans. Antennas Propag., 34, 276-280, doi:10.1109/ TAP.1986.1143830. 
Tintore, J., D.-P. Wang, E. Garcia, and A. Viudez (1995), Near-inertial motions in the coastal ocean, J. Mar. Syst., 6, 301-312, doi:10.1016/09247963(94)00030-F

van Haren, H., L. Maas, J. T. F. Zimmerman, H. Ridderinkhof, and H. Malschaert (1999), Strong inertial currents and marginal internal wave stability in the central North Sea, Geophys. Res. Lett., 26, 2993-2996, doi:10.1029/1999GL002352.

Xing, J., A. M. Davies, and P. Fraunie (2004), Model studies of near-inertial motion on the continental shelf off northeast Spain: A 3D/2D/1D model intercomparison, J. Geophys. Res., 109, C01017, doi:10.1029/ 2003JC001822.

A. Fontán, M. González, J. Mader, and A. Rubio, Marine Research Division, AZTI-Tecnalia, Herrera Kaia, Portualdea z/g E-20110, Pasaia, Gipuzkoa, Spain. (arubio@azti.es)

G. Reverdin, LOCEAN/, IPSL, INSU, CNRS, UPMC, boite 100, 4 Place Jussieu, F-75005 Paris, France. 